\title{
أحكام الافاع الشرعي في التشريع الجزائري
}

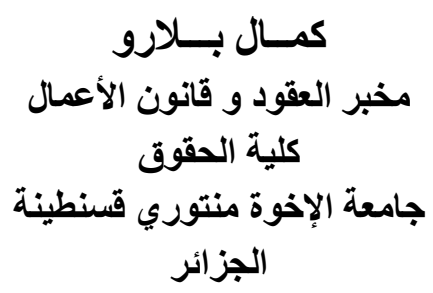

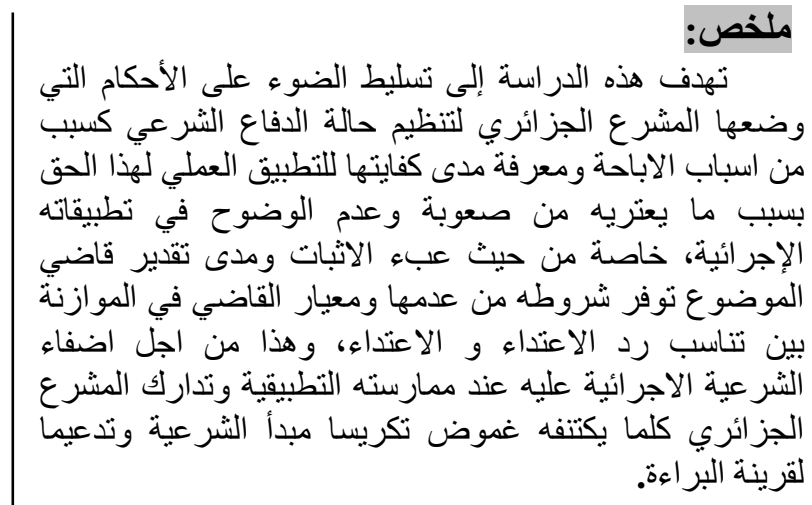

\begin{abstract}
:
The purpose of this study is to shed light on the provisions of the Algerian legislator to regulate the case of legitimate defense as a reason for permissibility and to know the adequacy of the practical application of this right because of the difficulty and lack of clarity in its procedural applications, And the criterion of the judge in the balance between the suitability of the response of aggression and aggression, and this in order to legitimize the procedural in the exercise of the application and remediation Algerian legislator whenever it is ambiguous enshrines the principle of legitimacy and in support of the presumption of innocence.
\end{abstract}

Keywords: grounds for permissibility, forensic defense, excellent cases, burden of proof, Supreme Court oversight. 


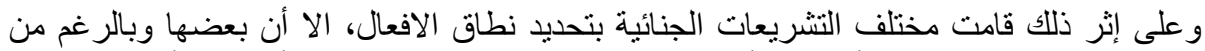

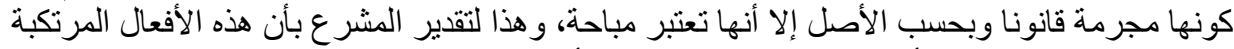

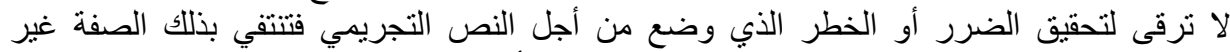
المشروعة عنها، وهذا المفهوم هو ما يطلق عليه تسمية أسباب الإباحة التي ينتفي في ظلإها الركن

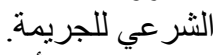

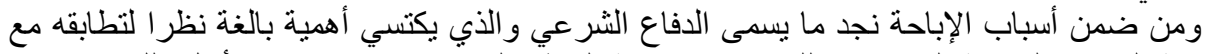

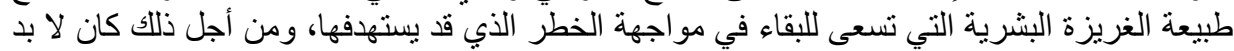

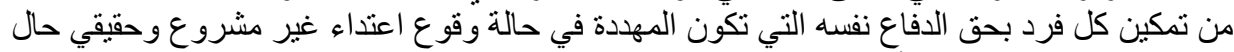

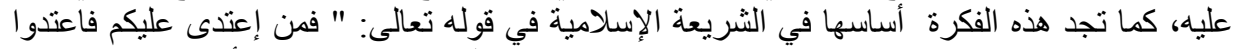

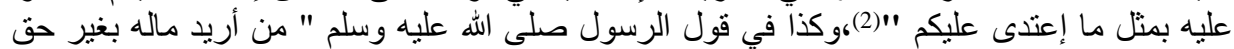
فقاتل فقتل فهو شهيد". و على أن المشرع الجزائري قد سلك نفس اتجاه باقي التشريعات و أخذ بالدفاع الثرعي كسبب من فئن

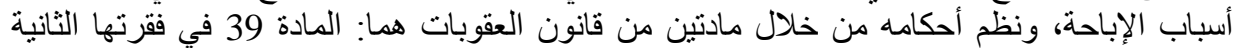

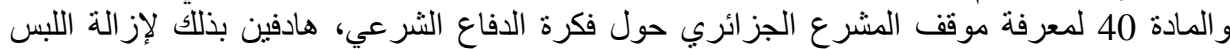

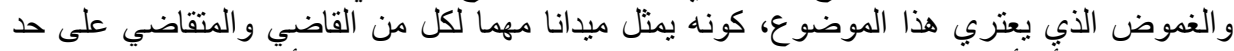

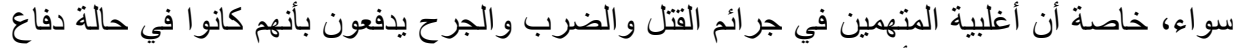

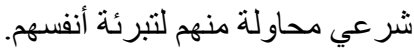
الاثكالية المطروحة تتحور حول: مالة ماهي الاحكام التي نظم بها المشرع الجزائري حالة الدفاع

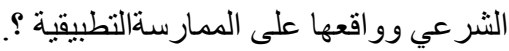

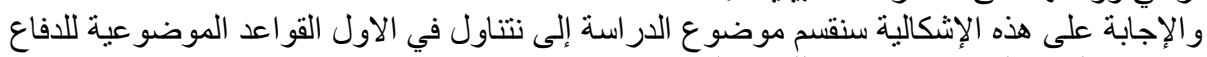
الثرعي، و الثاني القو اعد الإجر ائية للإفاع الثرعي. المبحث الأول المول

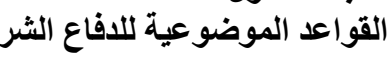

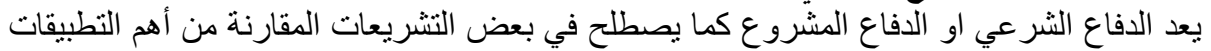

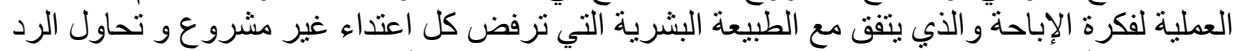

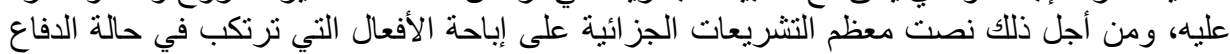

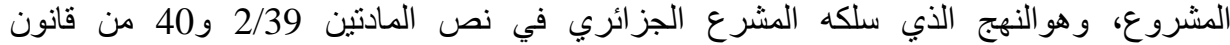

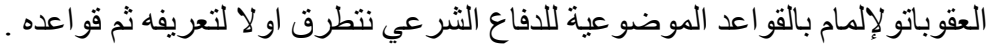

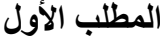

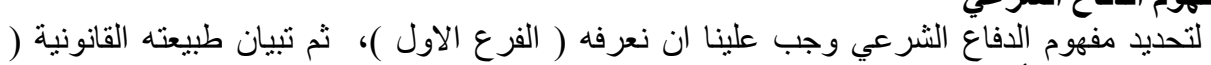
الفرع الثاني) ، وأخير نطاق تطبيقه ( الفرع عالثالث). تعريف الدفاع الشرعي

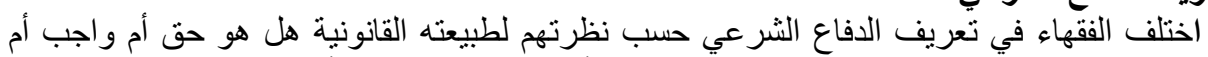

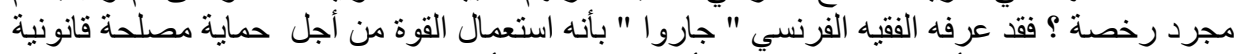

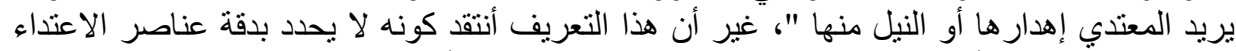

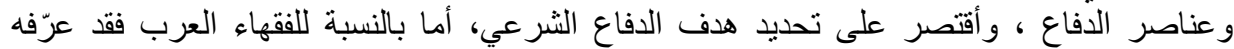

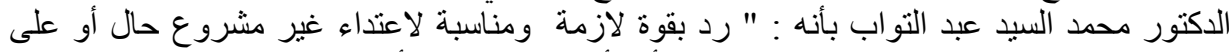

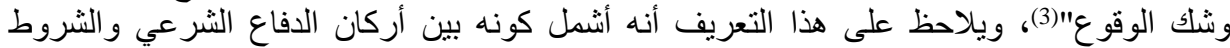


أما في الثريعة الإسلامية فالدفاع الثرعي هو واجب الإنسان في حماية نفسه ونفس غيره، و وعرضه فيه فئه

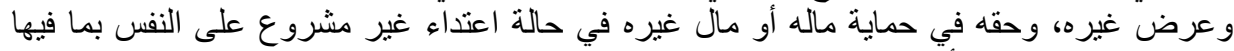

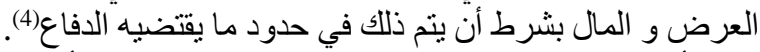

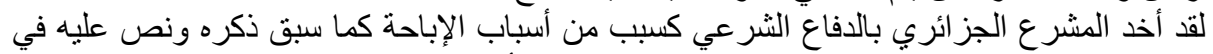

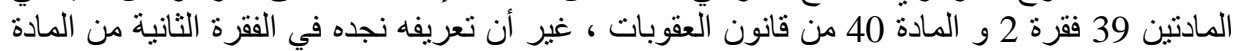

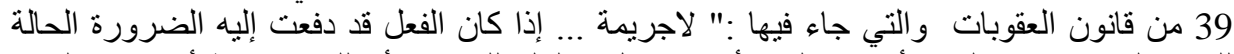

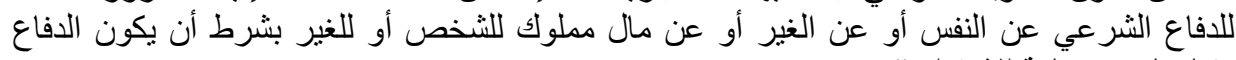

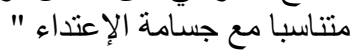
وحسب هذا النص فإن الدفاع الثرعي هو إستعمال للقوة اللازمة من إنبل فبل المدافع لرد الإعتداء الحال

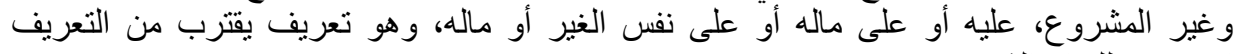

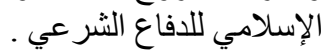
الفرع الثاني الثياني

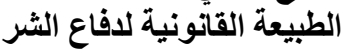

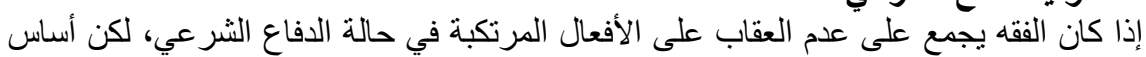

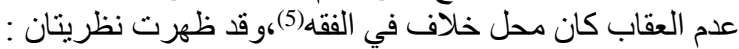

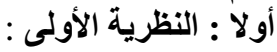

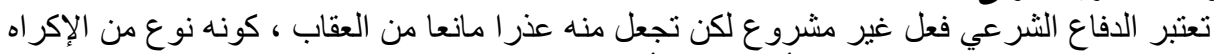

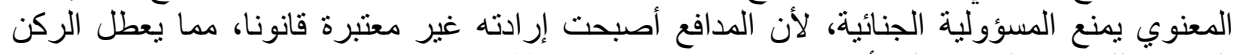

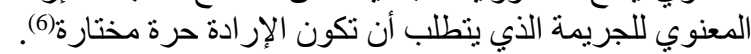

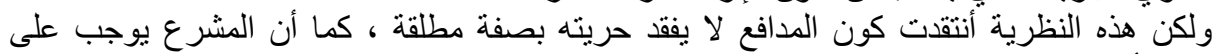

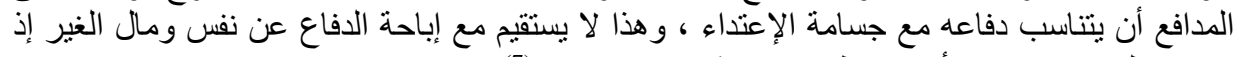

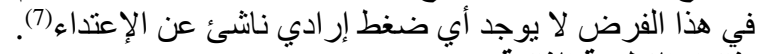

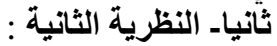

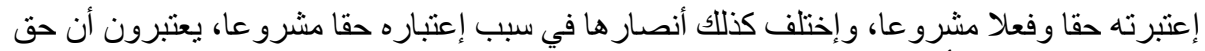

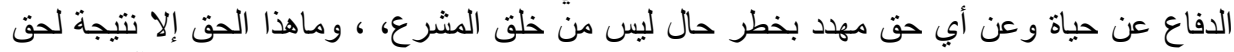

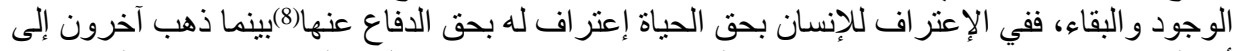

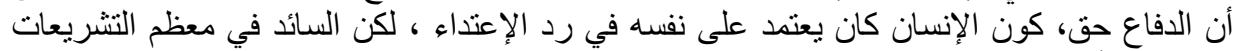

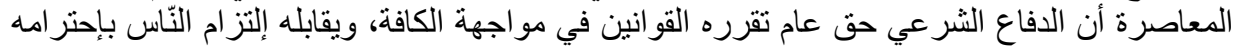
و وعدم مقاومة إستعمالك. الأله الفرع الثالث نطاق تطبيق الدفاع الشرعي

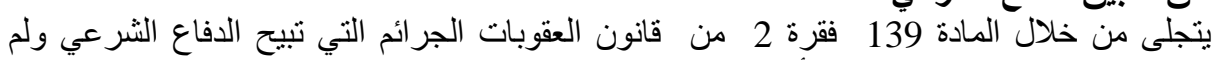
تحصر ها في جر ائم الاعتداء على العادة الأشخاص بل بل وسعت من من نطاقها: أولا : جرائم الاعتداء على النف ألفس:

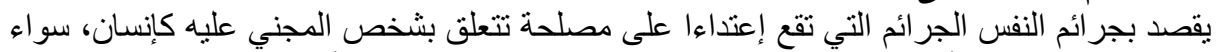

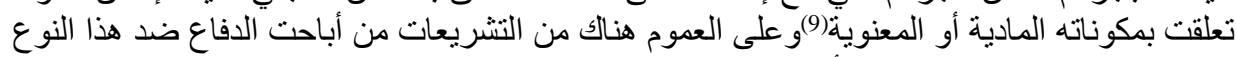

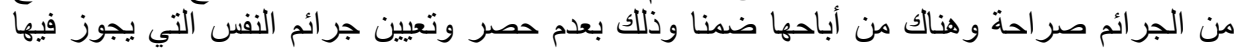

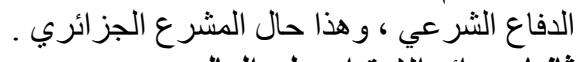

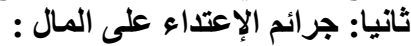

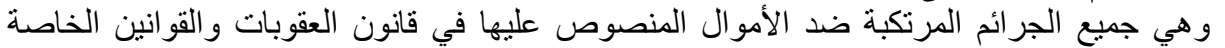

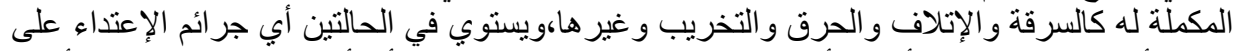
النفس أو الإعتداء على الأموال أن يكون الإعتداء على صاحب الثَأن أو على على غيره(10)، فقد أطلق الإعنى 
المشرع الجزائري حق الدفاع بالنسبة للغير إذا كان مهددا بالخطر وغايته في ذللك تحقيق التعاون بين

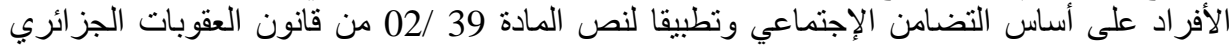

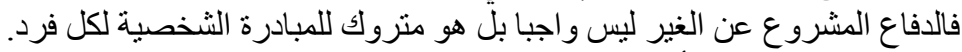

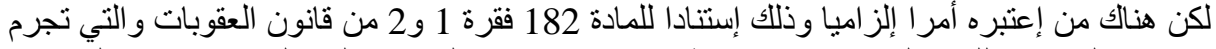

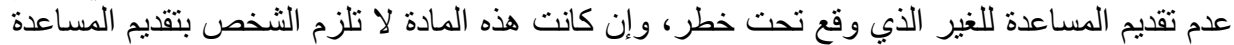

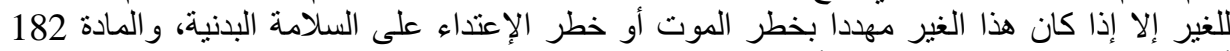
أوسع من مجال الدفاع المشروع لأن مصدر الخطر قد يكون الإنسان وقد تكون الطبيعة طبقا للفقرة من

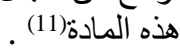
اما بخصوص الجرائم غير عمديةلم يحدد المشرع نطاق الجرائم التي تبيح الدفاع المشروع فسواء كانت الجريمة عمدية أو غير عمدية.

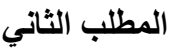
قو اعد الدفاع الثرعي الثي

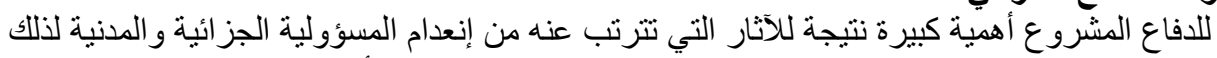

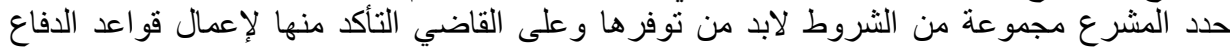

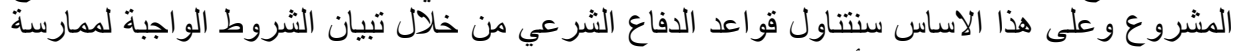
حق الدفاع المشروع ( الفرع الأول) ثم الحالات المثنازة للأفاع المشروع (الفرل الفرع الثاني)، واخير تجاوز حدود الدفاع المشروع (الفرع الثالث).

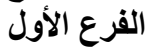
الثروط الواجبة لممارسة حق الدفاع الثرعي الإع الثرعي

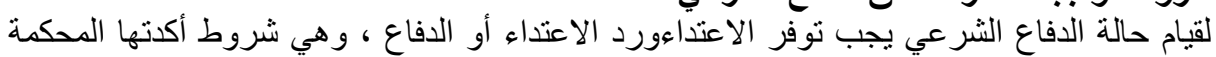

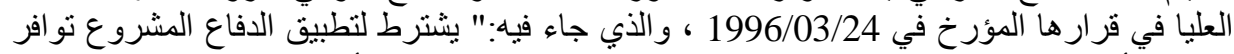

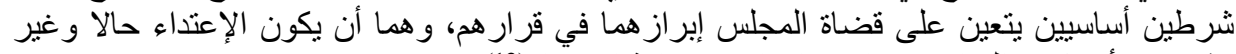

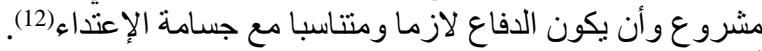
أولا : الشروط الواجب تون الواعرها في فعل الإعتداء :

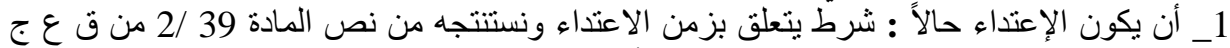

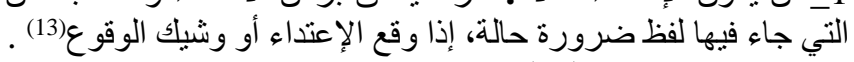

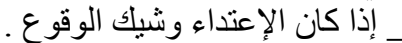

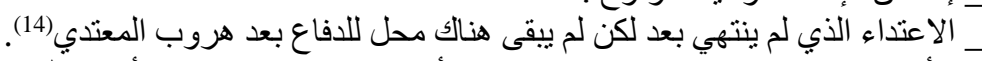

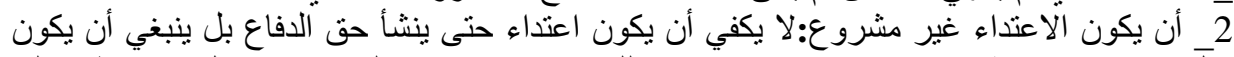

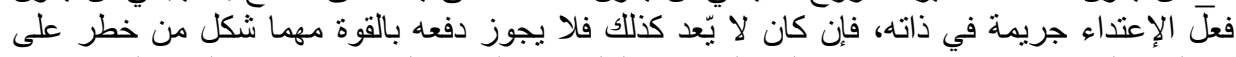

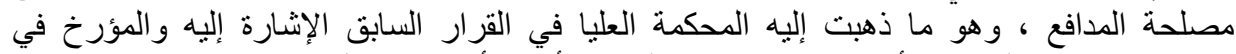

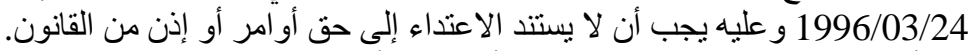

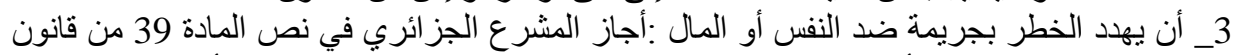

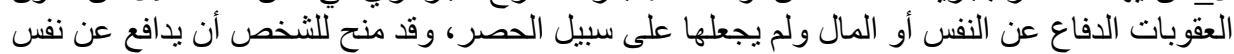

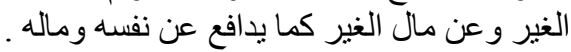

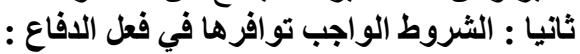

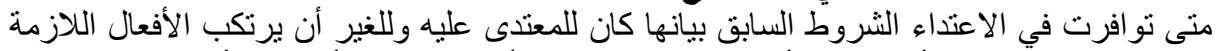
لدفع الاعتداء، لكن هذه الأفعال لا بد أن يتو افر فيها شرطين أساسين و هما: أن تكون أفعال الدفاع لازمة الأنة

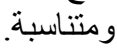

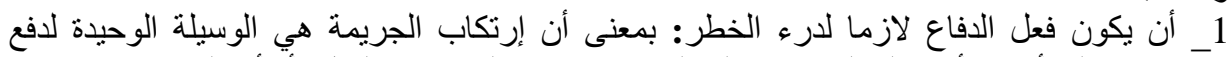

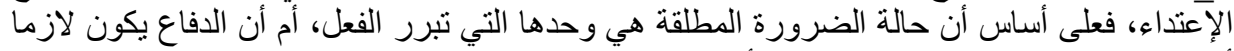

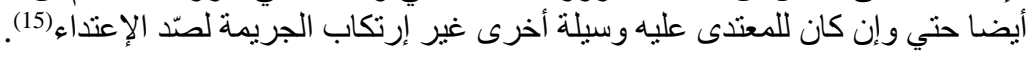


2__ رد متتاسب مع الاعتداء:وهذا الثرط ورد في نص المادة 2/39 من قانون العقوبات الجزائري

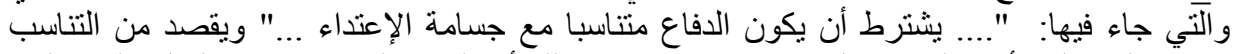

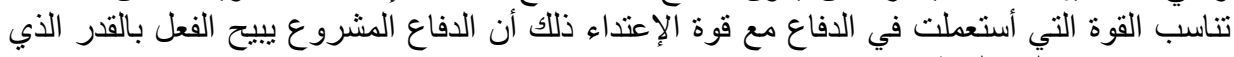

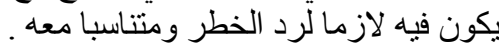

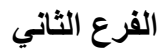
الحالات المتّتازة للافاع الشرعي

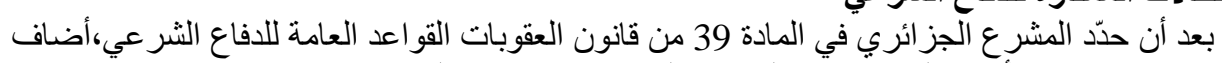

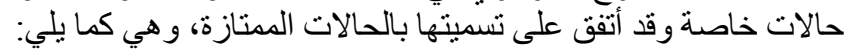

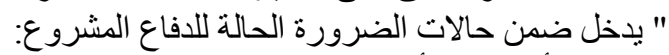

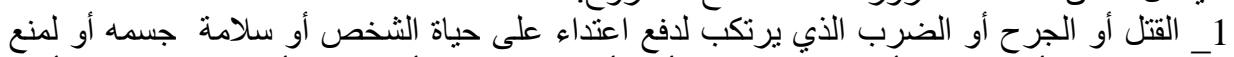
تسلَق الحواجز أو الحيطان أو مداخل المنازل أو الأماكن المسكونة أو نو ابعها أو كسر شيئ منها أثناء

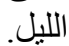

2 ـ الفعل الذي يرتكب للادفاع عن النفس أو عن الغير ضد مرتكبي السرقات أو النصب بالقوة"(16).

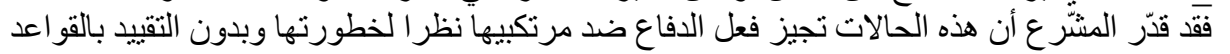

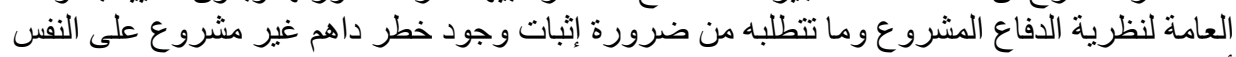

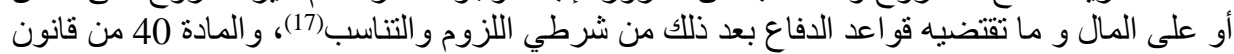

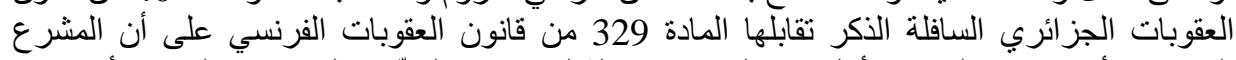

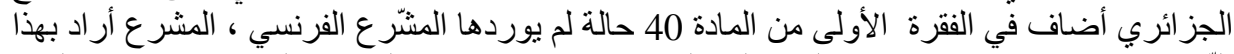

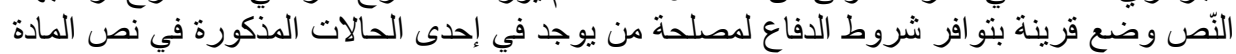

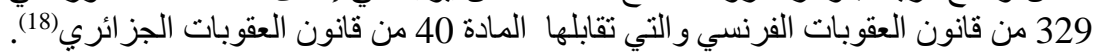

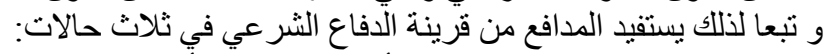

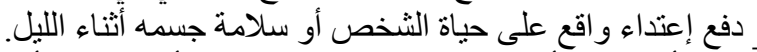

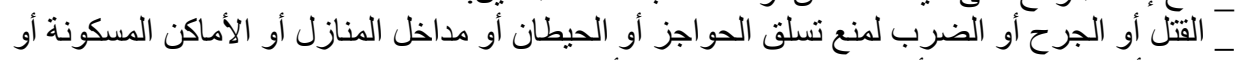

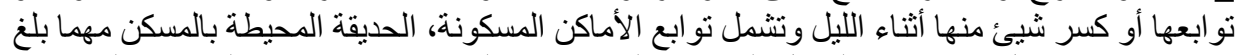

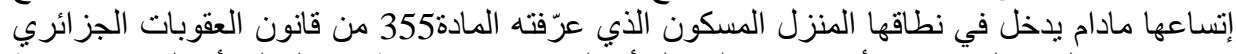

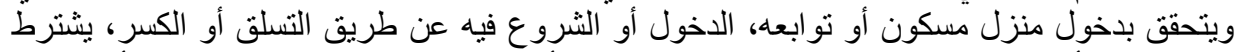

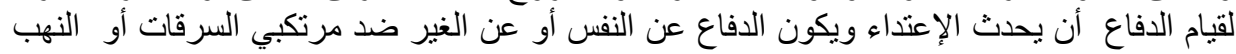

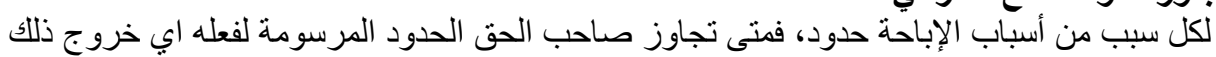

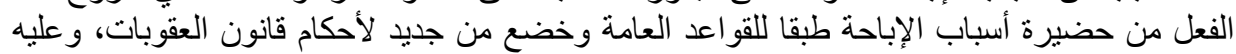

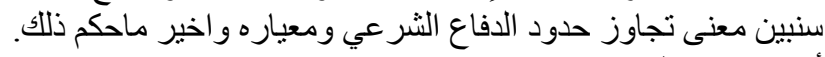
أولا : معنى التجاوز : ألمارز

لتحديد المقصود بالتجاوز ينبغي التفرقة بين شرط الخطر وشرط لزوم الدفاع من ناحية وبين شروط

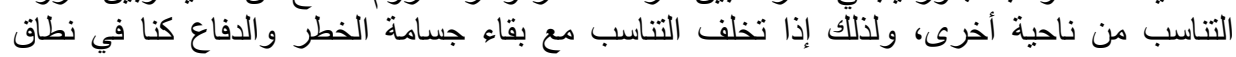

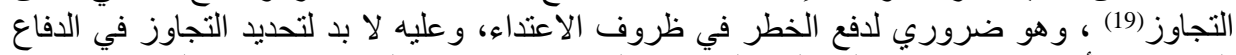

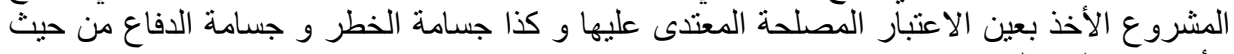
إختلف الفقه كذلك بشأن المعيار الواجب اعتماده في تقدير التجاور و انقسم إلى قسمين: 
يقوم على أن تقدير جسامة الاعتداء وخطورته يتعين أن يكون على أساس شخصي، أب أن تحديد

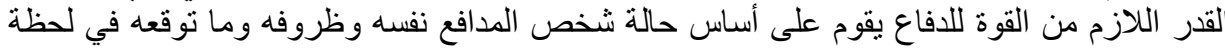
الدفاع وبصرف النظر عن كيفية سلوك شأل شخص عادي في مثل هذه الظروف.

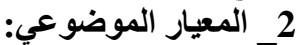
الآذي يأخذ بتصرفات ألثخص المعتاد في مثل ظروف الو اقعة ابي يقوم على اساس موضوعي .

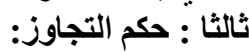

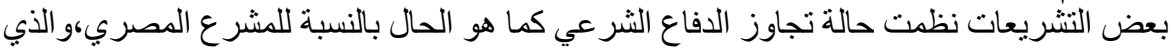

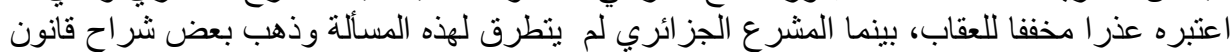

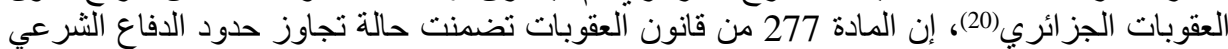

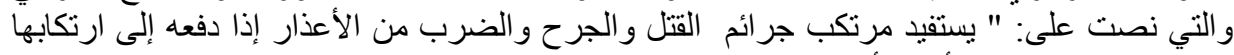

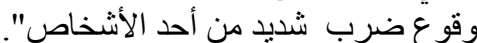

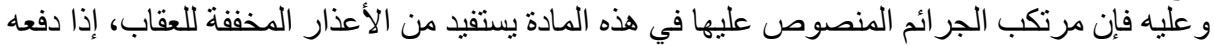

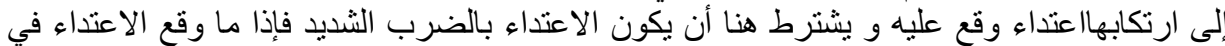

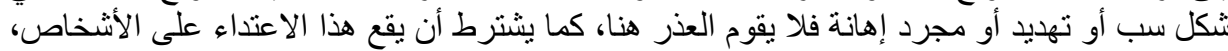

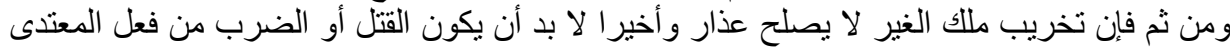
عليه نفسه(21) نجان و هذا ما جعل بعض شراح قانون العقوبات الجزائري، يعتبرون هذه المادة تنظم حالة تجاوز حدود

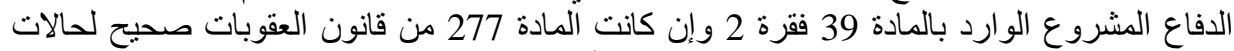

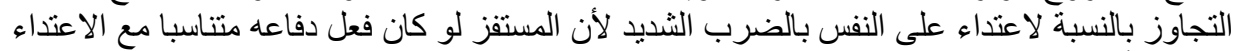

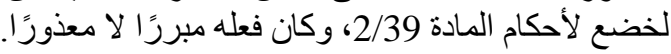
وكان ذلك بسبب رغبة من وقع عليه الضرب الثراب الثديد في الانتقام من الضرب الضرب و و إما أن من وقع عليه

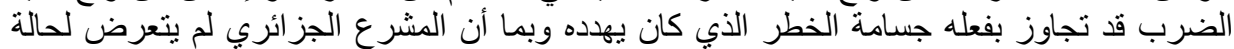

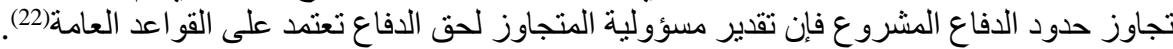

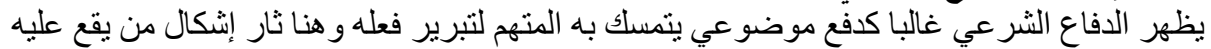

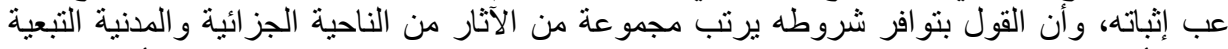

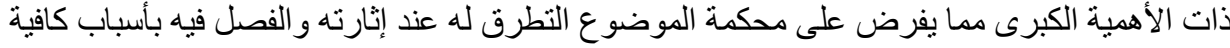
وهي تخضع في ذللك لرقابة المحكمة العليا.

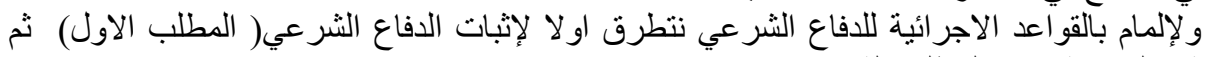

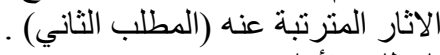

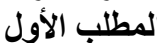
اثبات الدفاع الثرعي الثرال

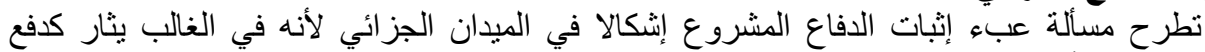

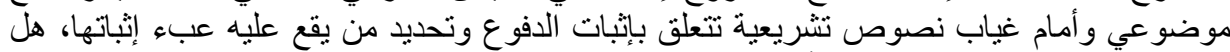
إثباته يقع على عاتق سلطة المتابعة أب النيابة العامة ؟

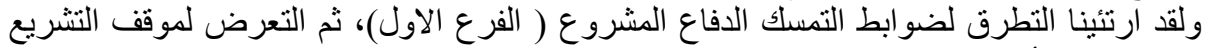
و القضاء من مسألة عبء إثبات الدفاع المشروع (الفرع الثنان الثني). 


\section{الفرع الأول}

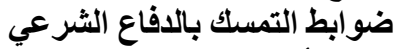

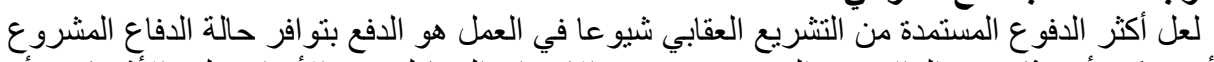

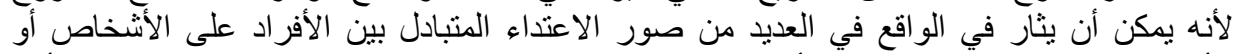

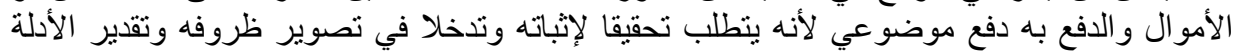

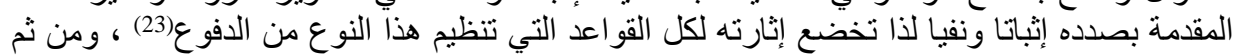

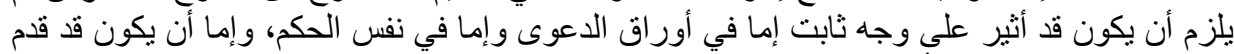

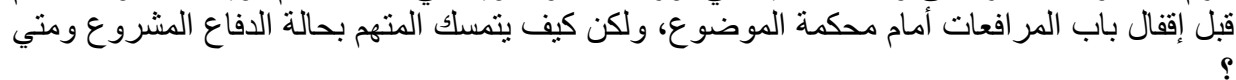

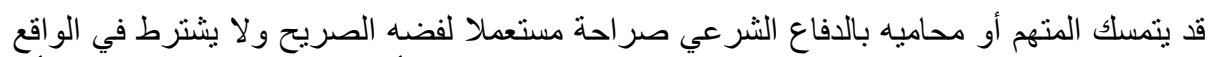

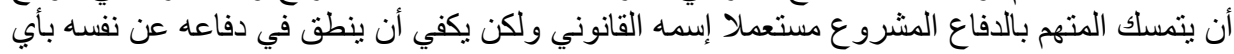
عبارة يفهم منها قيام الدفاع(24).

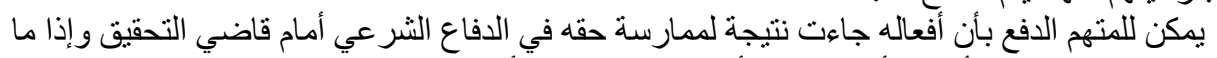

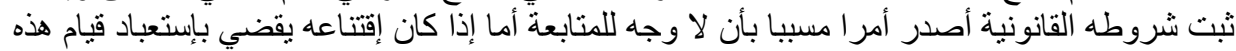

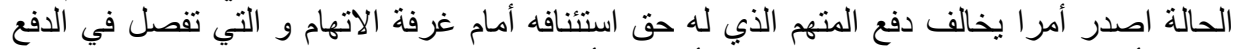

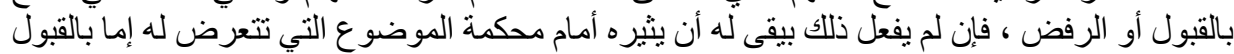

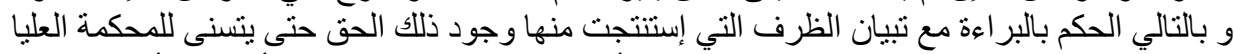

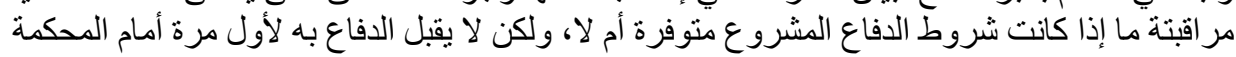
العليا إذا لم يسبق مانق إنى

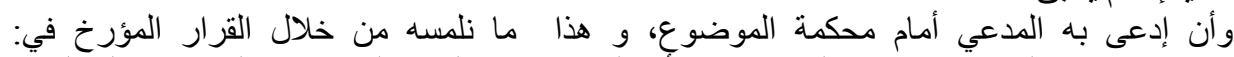

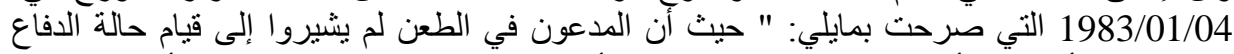

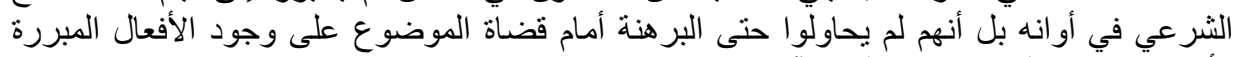

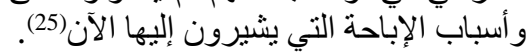
الفزع الثاني

موقف التشريع والقئياء من مسألة الإثبات

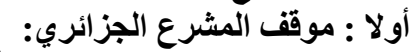

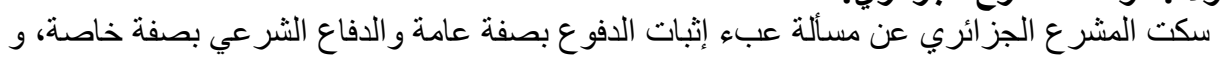

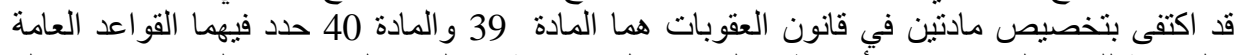

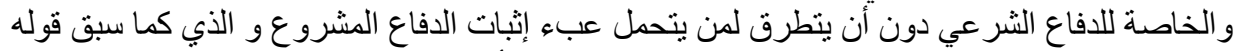

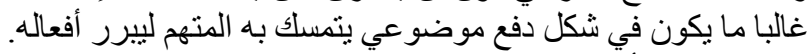

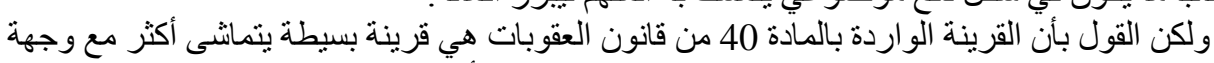

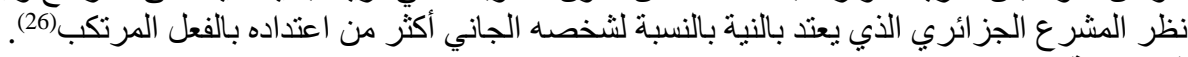
ثانيا: موقف القضاء:

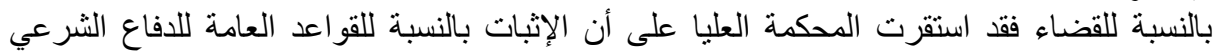

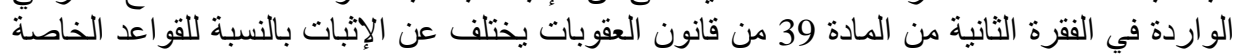

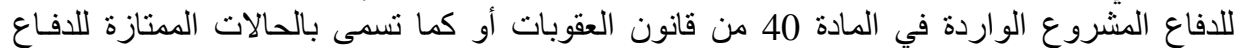

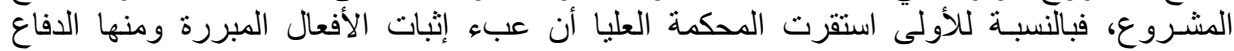
المشروع يقع على عاتق المتهم(27).

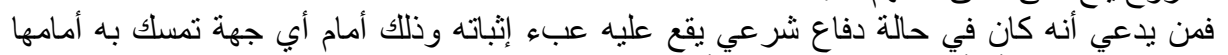

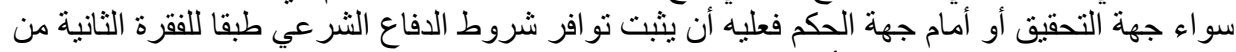

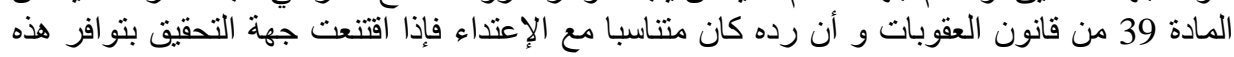


الثروط أصدرت أمر بإنتفاء وجه المتابعة، أما إذا لم تقتنع فتقوم بإحالته على المحكمة، هذه الأخيرة التي

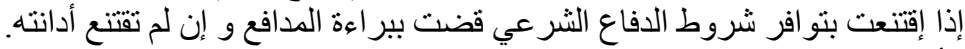

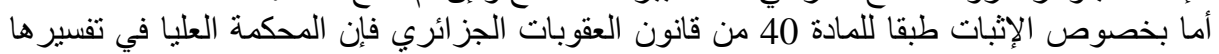

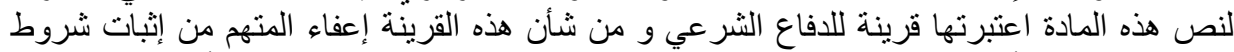

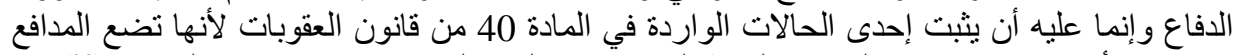

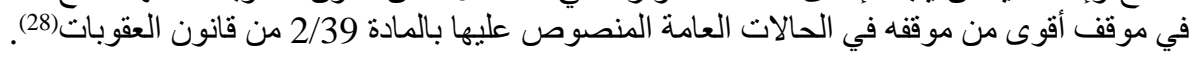

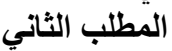
آثار الدفاع الثرعي الثي

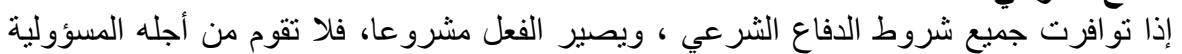

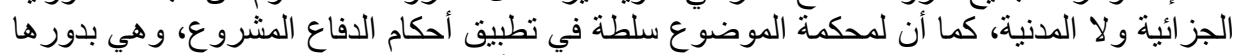

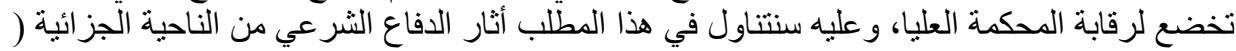
الفرع الاول)، سلطة قاضي الموضو الطوع ولية ورقابة التحكمة العليا ( الفرع الثاني).

آثار الدفاع الشرعي من الناحية الجزائية.

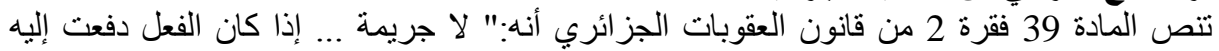

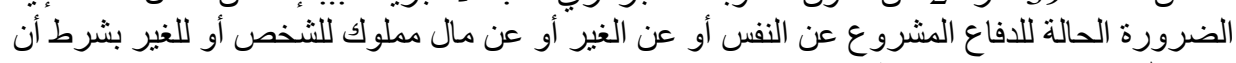

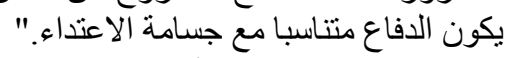

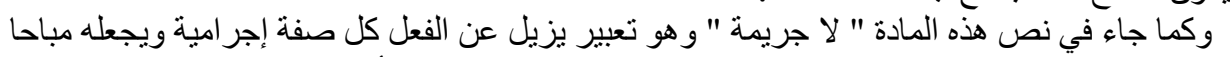

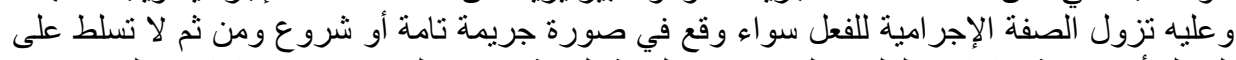

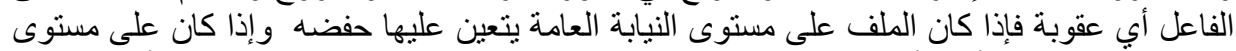

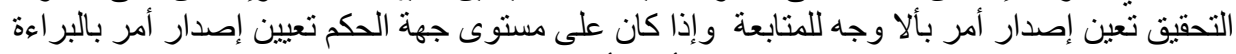

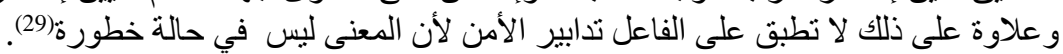

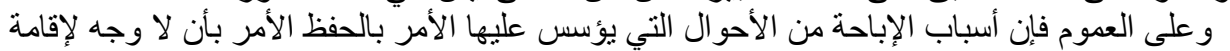

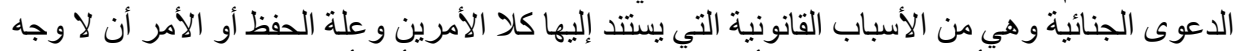

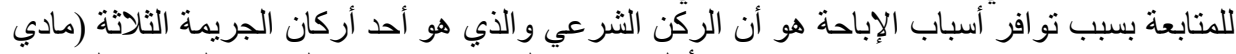

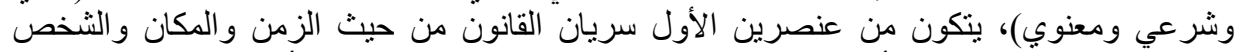

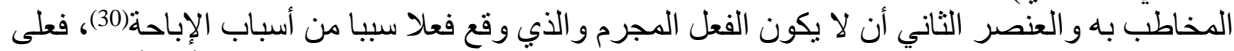

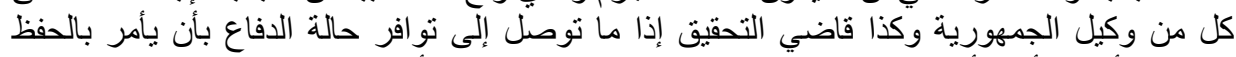

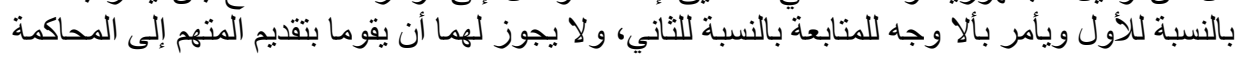

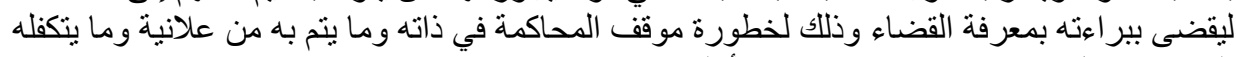

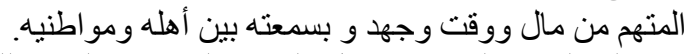

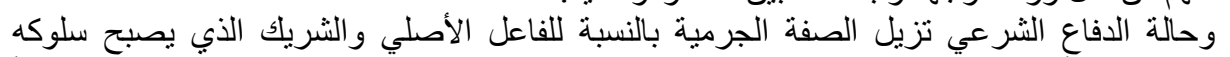

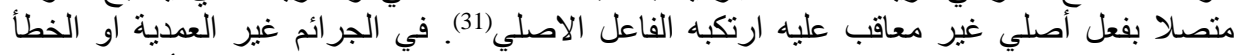

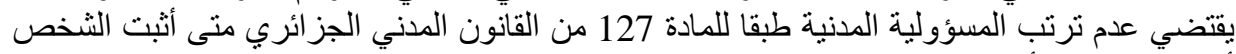
أن الضرر قد نشأ عن سبب لا يد فيه أو خطأ صدر من المضرور أو من الغير.

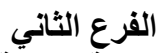
سلطة محكمة الموضوع ورقابة المحكمة العليا محكمة الموضوع ملزمة بالفصل في في الدفاعة الفماع الثشرعي إذا ما تمسك به المتهم أو إذا كانت الدعوى تثبت قيامه، هي تخضع في ذللك لرقابة المحكمة العليا. 


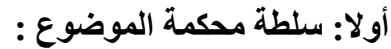

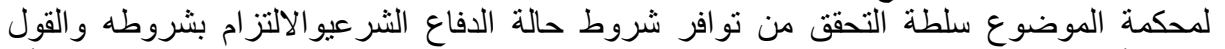

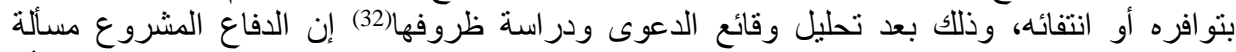

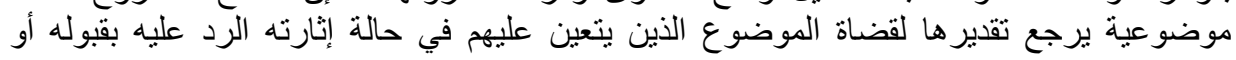

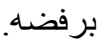
و هذا ما ذهبت إليه الدحكة العليا في قراريها الصادرين عن الغرفة الجنائية الثانية يوم 10 نوفئ نوفبر

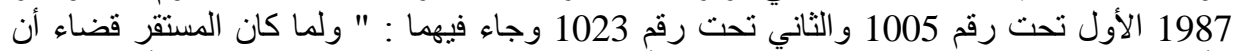

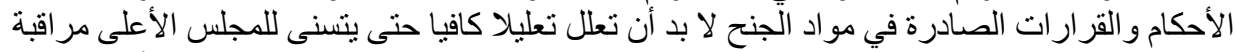

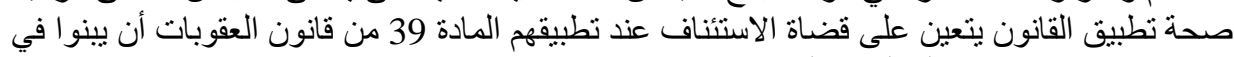

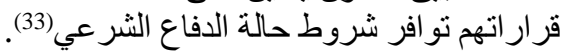
ثانيا : رقابة المحكمة العليا :

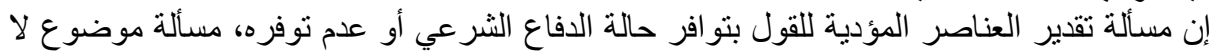

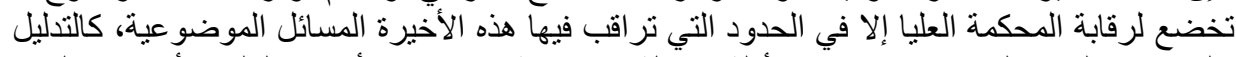

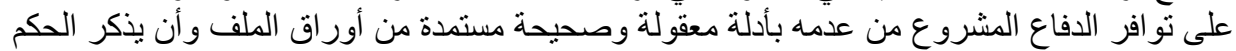

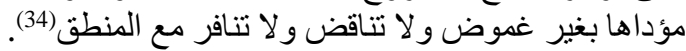

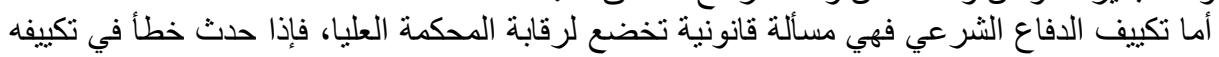

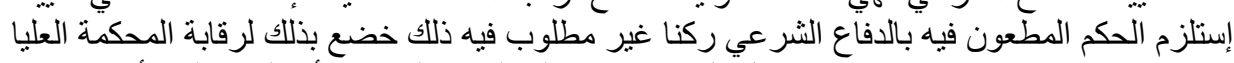

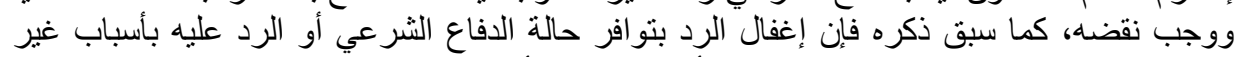

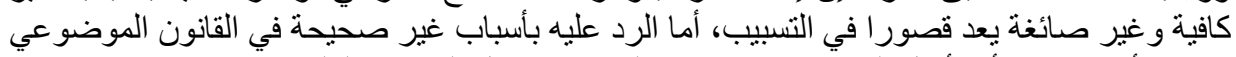

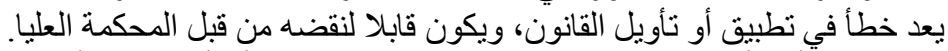

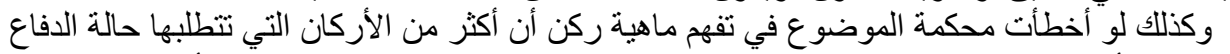

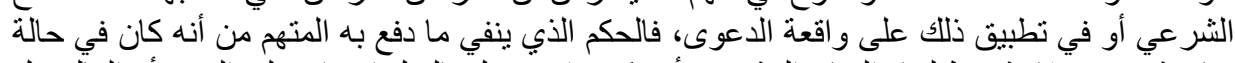

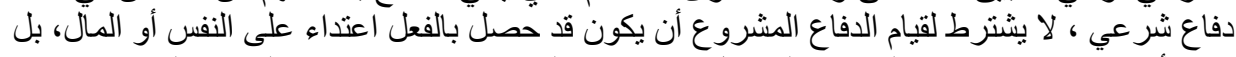

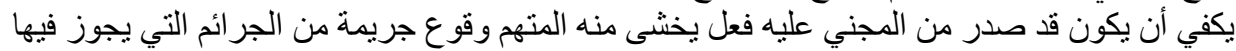

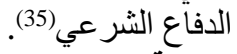

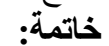

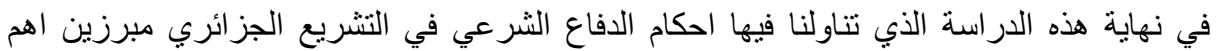

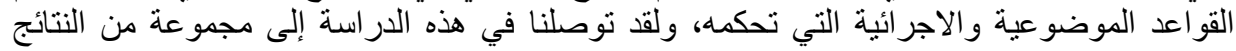

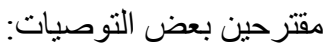

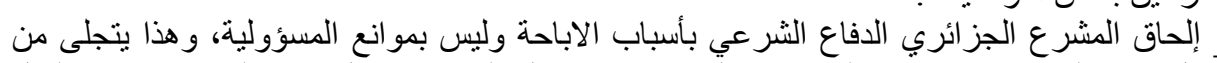

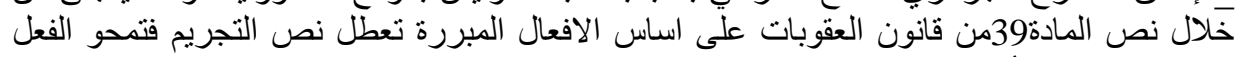

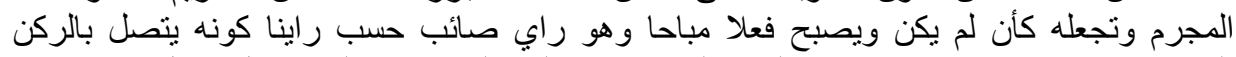

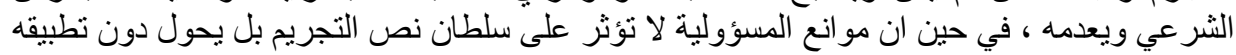

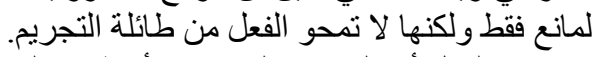

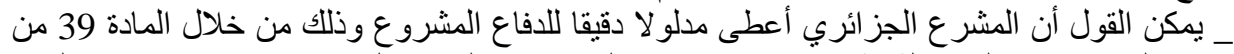

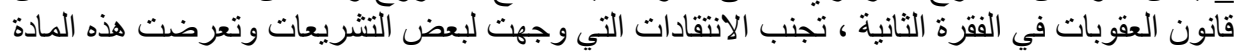

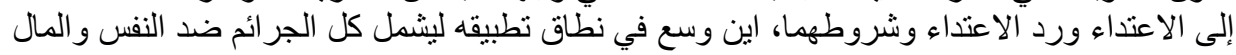

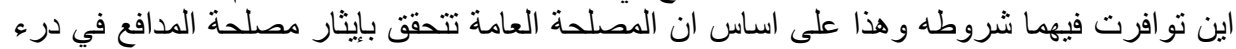
الاعتداء على مصلحة من بادر بالاعتداء فاصبح فعل المدافع حين لا يتيسر له الاستعانة بالسلطات فئرة

أحسن ما فعل المشرع في عدم حصر نطاق تطبيقه في جرائم النفس و المال فقط لأن العدالة الإنسانية

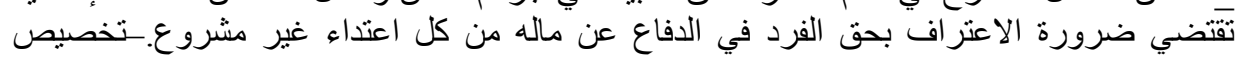


المادة 40 من قانون العقوبات لحالات خاصةمتى تو افرت، وهي ما أصطلح عليها بالحالات الممتازة

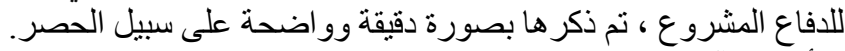

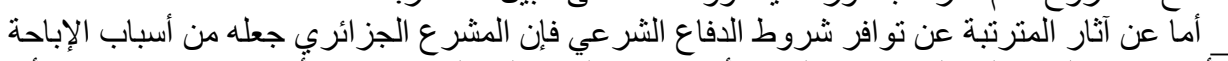

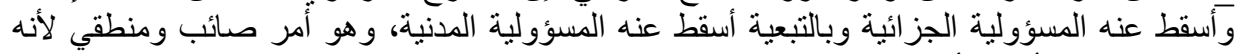

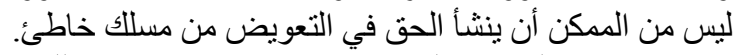

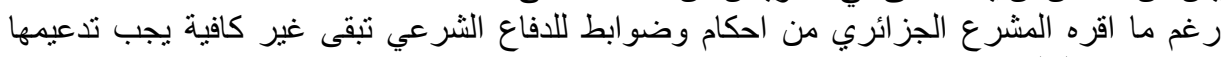

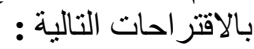

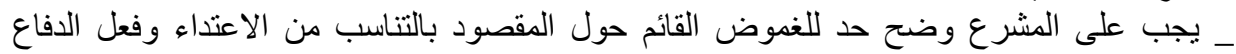

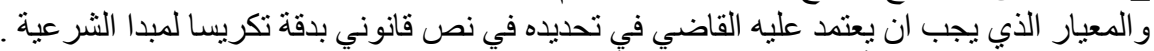

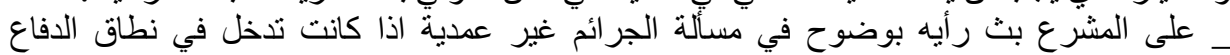

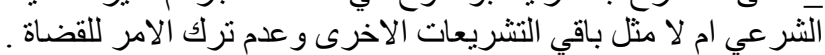

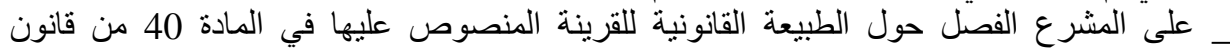

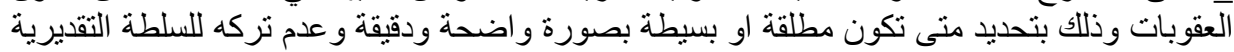

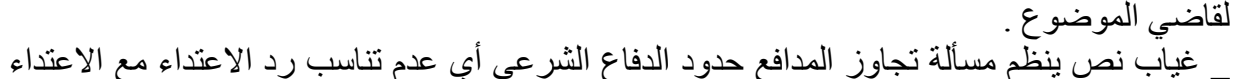

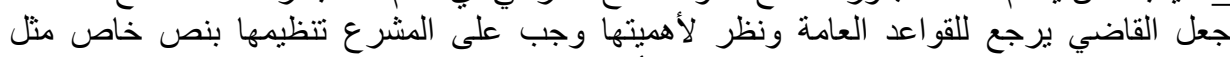

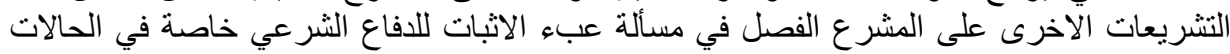

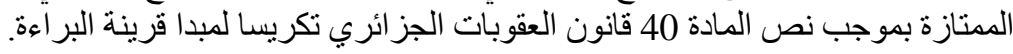

(1)- عبد: الفتاح مصطفى الصيفي، حق الدولة في العقاب، دار النهضة العربية، القاهرة، 1970، ص49.

(2) - (2)-سورة البقرة الآية 194.

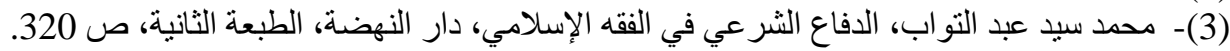

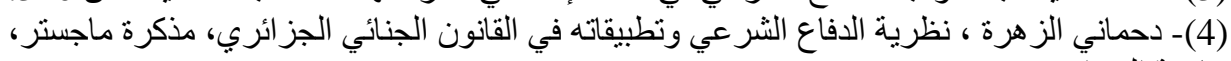

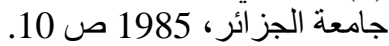

(5)- مأمون محمد سلامة، قانون العقوبات القسم العام، دار الفكر العربي، القاهرة، الطبعة الثالثة،

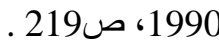

(6)- عبد الله سليمان، شرح قانون العقوبات الجزائري القسم العام الجزء الأول الجريمة، ديوان

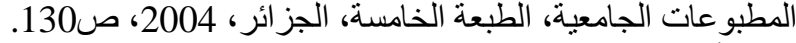

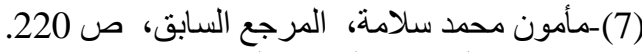

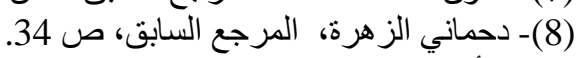

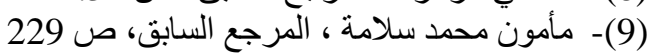
(10)- أحسن بوسقيعة، الوجيز في القانون الجزائي العام ، دار هومة ، الجزائر، الطبعة الحادية عشر ،

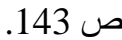

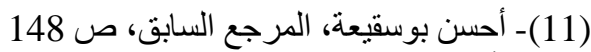

(12)- أحسن بوسقيعة،قانون العقوبات في ضوع صه الممارسة القضائية، منشورات بيرتي، الجزائر،

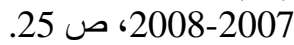
(13)-احسن بوسقيعة، الوجيز في القانون الجز ائي العام، ص 149 (14)-رضا فرج ، شرح قانون العقوبات الجزائري ( القسم العام )، ديوان المطبوعات الجان الجامعية،

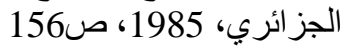
(15)- احسن بوسقيعة، المرجع السابق، ص 151 


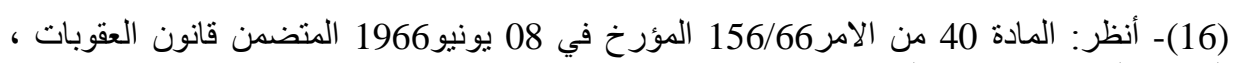

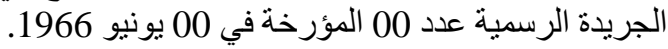

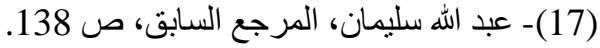

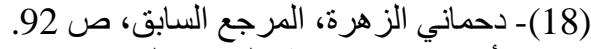

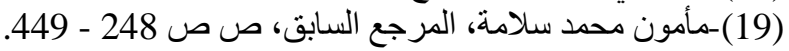

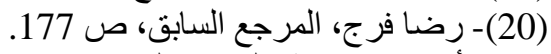

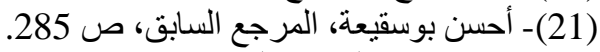

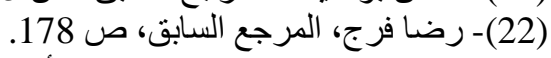

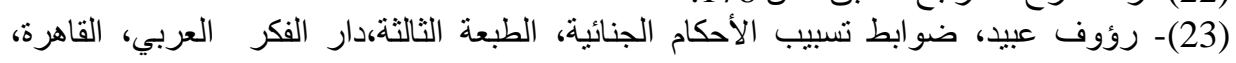

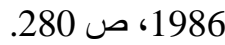

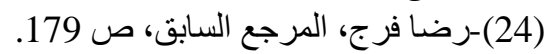

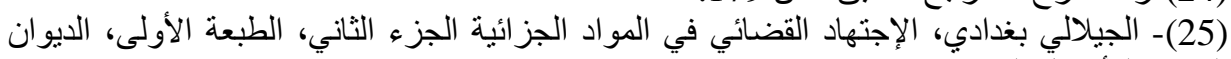

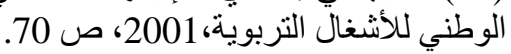

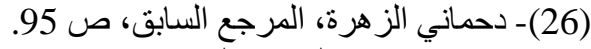

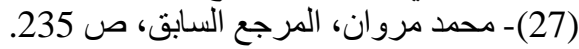

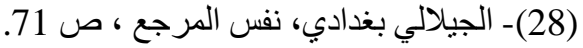

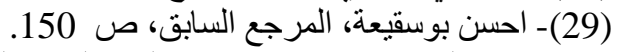

(30)-عبد الفتاح بيومي حجازي، سلطة الني، النيابة العامة في حفظ الأوراق والأمر بأن لا وجه لإقامة

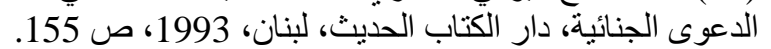

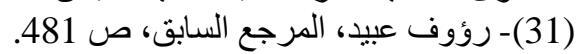

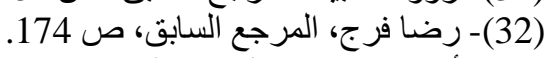

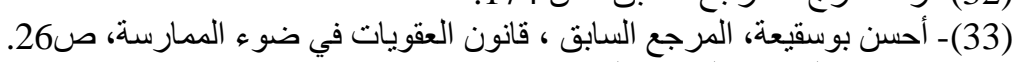

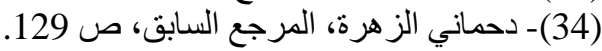

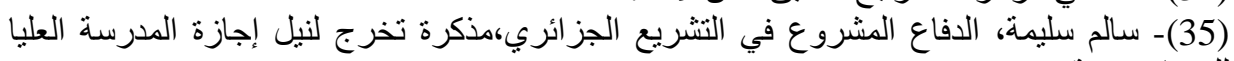

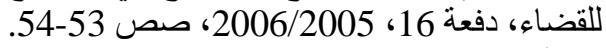

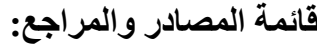

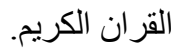

1- - الامر 66-156 المؤرخ في 8 يونيو 1966 المتضيمن قانون العقوبات الجزائري، الجريدة

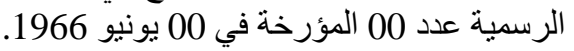

2- عبد الفتاح مصطفى الصيفي، حق الدولة في العقاب، دار النهضة العربية، القاهرة، 1970.

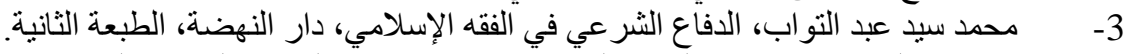

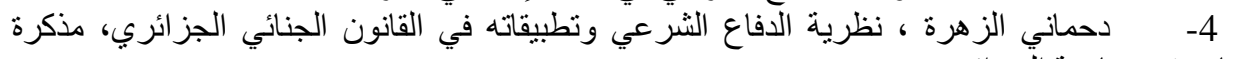

ماجستر ، جامعة الجز ائر ، مانس 1985.

5- مأمون محمد سلامة، قانون العقوبات القسم العام، دار الفكر العربي، القاهرة، الطبعة الثالثة،

.1990

6- عبد الله سليمان، شرح قانون العقوبات الجزائري القسم العام الجزء الأول الجريمة، ديوان

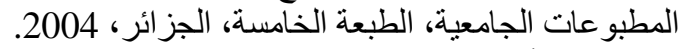

7- أحسن بوسقيعة، الوجيز في القانون الجز ائي العام ، الطبعة الحادية عشر ، دار هومة للطباعة

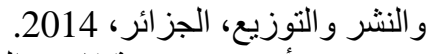

8- 808-2007 أحسن بوسقيعة،قانون العقوبات في ضوء الممارسة القضائية، منشورات بيرتي، الجزائر، 
9- رضا فرج ، شرح قانون العقوبات الجزائري الاحكام العامة للجريمة ، الطبعة الثانية ،

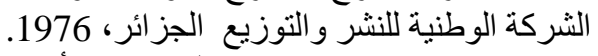

10- رؤوف عبيد، ضوابط تسبيب الأحكام الجنائية، الطبعة الثالثة،دار الفكر العربي، القاهرة، 11- الجيلالي بغدادي، الإجتهاد القضائي في المواد الجزائية الجزء الثاني، الطبعة الأولى، الديوان الوطني للأشغال التربوية، 12 - 2001.

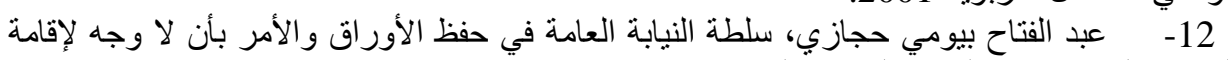

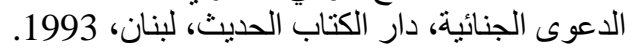
1- سالم سليمة، الدفاع المشروع في التشريع الجزائري،مذكرة تخرج لنيل إجازة المدرسة العليا لالقضاء، دفعة 16، 2006/2005. 